\title{
BMJ Open Mixed methods evaluation of a self- management group programme for patients with neuromuscular disease and chronic fatigue
}

\author{
Yvonne Veenhuizen (10 ,' Ton Satink, ${ }^{2}$ Maud JL Graff, ${ }^{1,3}$ Alexander CH Geurts, ${ }^{1}$ \\ Jan T Groothuis, ${ }^{1}$ Baziel GM van Engelen, ${ }^{4}$ Maria WG Nijhuis-van der Sanden, ${ }^{1,3}$ \\ Edith $\mathrm{HC}$ Cup $^{1}$
}

To cite: Veenhuizen $\mathrm{Y}$, Satink T, Graff MJL, et al. Mixed methods evaluation of a self-management group programme for patients with neuromuscular disease and chronic fatigue. BMJ Open 2021;11:e048890. doi:10.1136/ bmjopen-2021-048890

- Prepublication history and additional supplemental material for this paper are available online. To view these files, please visit the journal online. (http://dx.doi.org/10.1136/ bmjopen-2021-048890)

Received 10 January 2021 Accepted 06 August 2021

A) Check for updates

(c) Author(s) (or their employer(s)) 2021. Re-use permitted under CC BY-NC. No commercial re-use. See rights and permissions. Published by BMJ.

For numbered affiliations see end of article.

Correspondence to Dr Yvonne Veenhuizen; yvonne.veenhuizen@ radboudumc.nl

\section{ABSTRACT}

Objective To obtain insight into experiences of patients with a neuromuscular disease and chronic fatigue and their healthcare professionals regarding content and delivery of a multidisciplinary outpatient self-management group programme to improve social participation. This will inform future implementation.

Design A mixed method study alongside a randomised controlled trial.

Setting University hospital, rehabilitation centre and community health centre.

Participants 29 patients with a neuromuscular disease and chronic fatigue and 13 healthcare professionals participated in this mixed methods study.

Intervention Multidisciplinary group programme, called Energetic, consisted of a 4 months intervention with weekly meetings and covered four modules: (1) individually tailored aerobic exercise training; (2) education about aerobic exercise; (3) self-management training in applying energy conservation strategies and (4) implementation and relapse prevention in daily life.

Main measures Quantitative data were collected by a questionnaire measuring patients' ( $n=25$, all completed the programme) satisfaction with the perceived results, content and delivery of the programme. Qualitative data were collected by individual and focus group interviews to gain insight in the experiences of patients $(n=18)$, next of $\operatorname{kin}(n=2)$ and healthcare professionals $(n=13)$ with facilitators and barriers to programme implementation. Results Patients were satisfied with the number and length of the sessions, the different modules and the therapists. Analysis of the interviews led to five themes: (1) the combination of modules makes a complete picture, (2) the programme is physically and mentally intensive, (3) the group setting is valuable, (4) small variations in delivery occur in different settings, (5) therapists are coaches. Suggestions for programme improvement include a combination of face to face and e-health, enhancement of therapists' skills in guiding group interventions and inclusion of more booster sessions to evaluate and maintain self-management competencies. Conclusions The Energetic programme could be implemented in different healthcare settings and group settings, and a combination of modules proved to be a facilitator for improving self-management.

Trial registration number NCT02208687.
Strengths and limitations of this study

- A mixed method approach resulted in more insight in experiences of participants and professionals with a self-management group programme using questionnaires and interviews on the content and delivery of the programme.

- To obtain different perspectives, patients that participated in the programme and those that dropped out were interviewed as well as caregivers and different healthcare professionals involved in the delivery of the programme.

- Experiences from participants and professionals from three different healthcare settings were obtained to get insight in barriers and facilitators to implement the programme in these different settings.

- Only few partners of participants were interviewed, which may have led to a lack of saturation regarding the partners' perspective.

- Different strategies were used to enhance the trustworthiness of the findings; independent researchers were involved in carrying out the interviews, and there was triangulation of data collection methods.

\section{INTRODUCTION}

As there is no cure for most neuromuscular diseases (NMDs), managing the symptoms is essential for patients with NMD to participate in daily activities. More than $60 \%$ of patients with NMD report fatigue as their most disabling symptom. ${ }^{1-3}$ A self-management outpatient group programme, called Energetic, has been developed to improve the social participation and physical endurance of patients with NMD and chronic fatigue. ${ }^{4}$ This programme combines aerobic exercise training (AET), ${ }^{1}$ education about AET and energy conservation management (ECM) ${ }^{5}$ with relapse prevention and implementation in daily life. It is supervised by trained physical and occupational therapists (figure 1 ) ${ }^{46}$ The programme supports patients in acquiring 


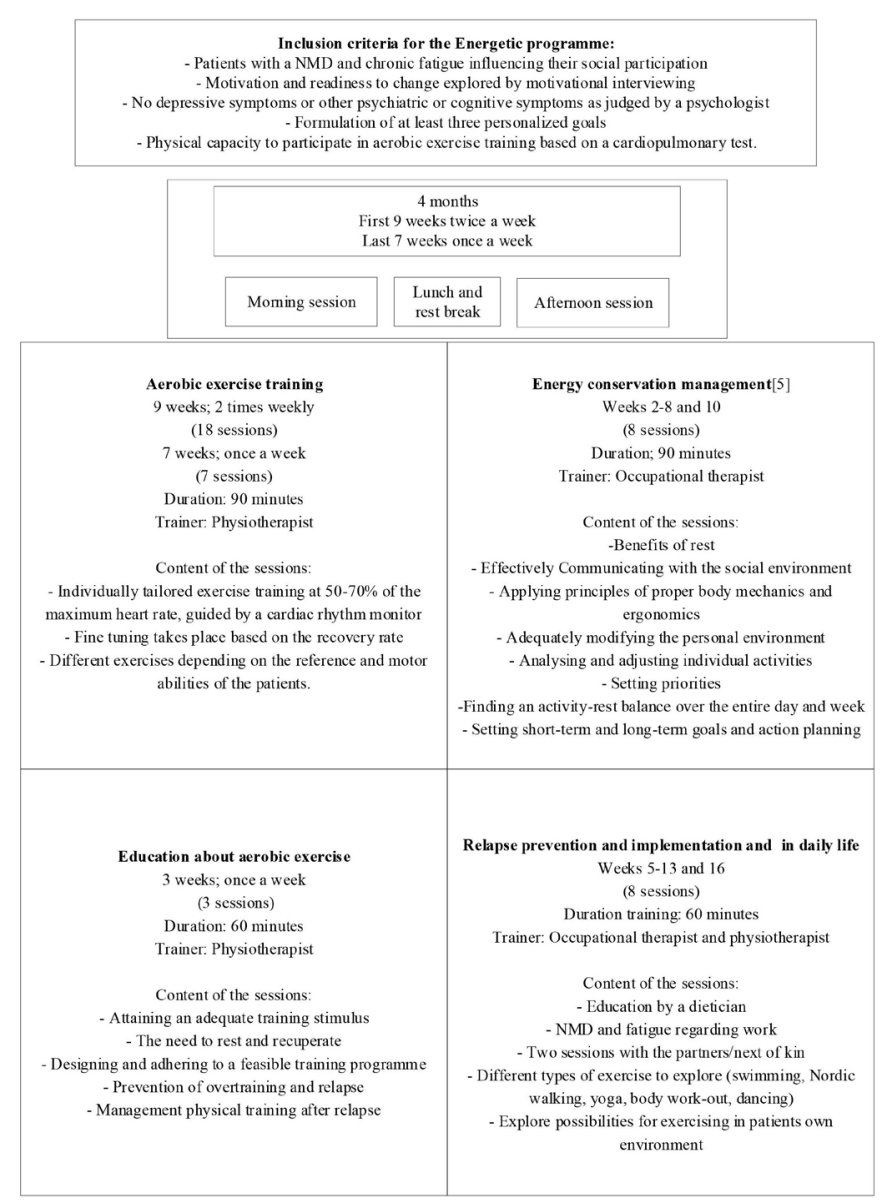

Figure 1 Content of the Energetic programme delivered by physical therapists and occupational therapists. NMD, neuromuscular disease.

and implementing self-management skills for behavioural change in daily life and for preventing relapse in the long term. ${ }^{4}$ The behavioural change techniques include individual goal setting, problem solving, action planning and feedback from peers. ${ }^{7-9}$

A recent randomised controlled trial (RCT) showed that, compared with usual care, the Energetic programme resulted in a significant improvement of social participation, assessed with the Canadian Occupational Performance Measure (COPM) ${ }^{1}$ and better physical endurance, assessed with the $6 \mathrm{~min}$ walking test directly after the intervention and at 3 and 11 months follow-up. ${ }^{6}$ The RCT only presented results from quantitative outcome measures, not the patients' and healthcare professionals' experiences with the intervention.

This study, therefore, presents a mixed method approach to the evaluation of the Energetic programme to gain insight in the perceived satisfaction of patients and healthcare professionals with the programme and the factors influencing the intervention. This evaluation was performed in order to provide suggestions for improvement of the content and the delivery of the intervention, the perceived impact, patient selection, timing of the intervention and for further improvement and implementation of the Energetic programme in different clinical settings. The research questions were: what is the perceived satisfaction with the Energetic programme and what are the facilitators and barriers regarding the impact, content and delivery of the Energetic programme?

\section{METHODS \\ Study design}

We used a mixed methods study design that combined quantitative and qualitative techniques for the evaluation of experiences of the facilitators and barriers regarding the Energetic programme. ${ }^{10-13}$ A questionnaire was developed to measure satisfaction of patients with the perceived results, content and delivery of the programme. Qualitative data were collected to gain insight into the experiences of patients and healthcare professionals and into facilitators and barriers regarding the Energetic programme. We used a combination of individual interviews for in-depth experiences and focus group interviews to stimulate interaction and discussion among patients.

\section{Intervention}

Energetic was delivered as a self-management multidisciplinary outpatient rehabilitation programme in small groups, with a minimum of 4 and a maximum of 8 patients per group. It was offered by trained physical and occupational therapists at three different clinical settings in the Netherlands: (1) Radboud University Medical Center (Nijmegen; study coordination), (2) rehabilitation centre Klimmendaal (Arnhem) and (3) community health centre Buitenlust (Venray). In all settings, Energetic was delivered during a 4-month period, in which patients attended the programme twice a week during the first 9 weeks and once a week during the last 7 weeks (morning and afternoon programme) (figure 1). In the same time periods, patients were requested to perform AET at home once a week (first 9 weeks) and twice a week (last 7 weeks). AET and self-management strategies were tailored to the individual patients as much as possible. In two sessions, a partner or next of kin was involved. The Energetic programme consisted of the following modules; (1) AET, (2) education about AET, (3) ECM ${ }^{5}$ and (4) relapse prevention and implementation in daily life. Before inclusion the occupational therapist assessed the motivation and readiness to change as well as the ability to formulate at least three personalised participation goals. Details of the intervention have been reported previously. $^{46}$

\section{Training of the therapists}

In each setting, one occupational and one physical therapist received a 1-day training 4 months before the start of the programme. In addition, a detailed manual with the content and schedule for each session was provided to each therapist. The 1-day training programme focused on: (1) knowledge related to the pathophysiology of different NMDs, (2) the rationale for the content of the Energetic programme, (3) the theoretical perspective on 
self-management and behavioural change techniques and (4) how to organise the Energetic programme in the local clinical setting. During the delivery of the programme, all therapists joined three additional education and discussion meetings. These intervision meetings aimed to facilitate the exchange of experiences regarding programme content and delivery among therapists and to support the adherence to the programme.

\section{Participants}

Patients included in the RCT were recruited at the departments of rehabilitation, neurology and internal medicine of the Radboud University Medical Center, as well as in the other participating centres. The Dutch patient association for NMD ('Spierziekten Nederland') facilitated recruitment by providing study information on their website, in their magazine and by email. The group who received the Energetic programme consisted of 8 men and 21 women (mean age 52 years, range 20-74 years) with a variety of NMD diagnoses (facioscapulohumeral dystrophy, inclusion body myositis, mitochondrial myopathy). Detailed information about the inclusion and exclusion criteria and baseline characteristics has been reported elsewhere. ${ }^{46}$ For this evaluation, all patients in the intervention group were asked to fill in the satisfaction questionnaire. Ten consecutive patients and seven partners or next of kin from the first two Energetic groups were asked by email to participate in an individual semistructured interview. Additionally, 19 patients were asked face-to-face during the intervention to participate in focus groups. All healthcare professionals involved in the organisation (secretary), recruitment (physicians) and delivery of the Energetic programme (occupational therapists and physical therapists) $(n=13)$ were asked to participate in individual semistructured interviews.

\section{Data collection}

\section{Satisfaction questionnaire}

A questionnaire was developed using statements regarding the satisfaction with the results, the content of the Energetic modules, the frequency and length of the therapeutic sessions, the organisation and the therapists that delivered the programme (online supplemental appendix A). The questionnaire contained 42 statements; for 21 statements the level of agreement was measured with an ordinal four-point rating scale from 'not at all' to 'entirely'; for 18 statements an ordinal rating scale was used ranging from 1 (not satisfied at all) to 10 (maximally satisfied); and three open questions were asked to evaluate the perceived valuable aspects of Energetic. Patients were also invited to provide narrative comments on what they would like to improve in the programme. All patients received the questionnaire after they had finished the programme and were asked to complete it independently and anonymously.
Individual and focus group interviews

Semistructured interview guides with non-directive, open-ended questions were made for the interviews. ${ }^{14}$ The individual interviews with the patients were held at their homes, 4 months after they had finished the Energetic programme. The healthcare professionals were interviewed in their work setting. One therapist was interviewed by videocall. The individual interviews with the patients and healthcare professionals were conducted by research assistants who were not involved in delivery of the Energetic programme. One research assistant led the conversation and the other made notes and observations. The individual interviews lasted approximately $60 \mathrm{~min}$. The focus group interviews with the patients were organised at the three different clinical locations. They took place immediately following the last session of the programme and lasted $60-90 \mathrm{~min}$. The focus groups were conducted by two research occupational therapists who were experienced with qualitative research and knowledgeable of the Energetic programme, but who were uninvolved in the delivery of the programme.

At the start of the interviews, the aim of the research, the procedures and the privacy policy were explained and there was ample opportunity to ask questions before written informed consent was obtained. The patients were interviewed regarding their experiences with the content and delivery of the Energetic programme. The healthcare professionals were interviewed regarding their experiences with the delivery of the programme (online supplemental appendix B). Additionally, the logs and notes of the education and discussion meetings with the therapists were collected for qualitative analysis. Patients (PA), partners or next of kin (NoK) and healthcare professionals, including occupational therapists (OT), physical therapists (PT), physicians (PHYS) and secretary (SC), were given a number to ensure their anonymity. The setting was indicated as Nijmegen (N), Arnhem (A) or Venray (V).

\section{Data analysis}

Questionnaires

We analysed the data from the satisfaction questionnaire using descriptive statistics. ${ }^{15}$ Statistical analyses were carried out with SPSS v.22.

\section{Interviews and open questions}

The aim of the constant comparative analysis was to identify overarching themes regarding facilitators and barriers related to the content and delivery of the Energetic programme. The analysis process consisted of the following steps $^{16}$ : (1) individual and focus group interviews were transcribed verbatim; (2) qualitative data (transcripts of the individual and focus group interviews, text of the open questions of the satisfaction questionnaire and notes of the therapists' meetings) were imported into analysis software for qualitative data (Atlas ti, V8.0.34); (3) and were read by the first author (YV) to get familiarised; (4) open data coding was conducted by 
Table 1 Participants in the qualitative interviews

\begin{tabular}{|c|c|c|c|c|}
\hline Participants & $\begin{array}{l}\text { Patient (individual } \\
\text { interviews) } \\
\text { sex (F/M), } \\
\text { age category, diagnoses, } \\
\text { work }\end{array}$ & $\begin{array}{l}\text { Patients (focus group) } \\
\text { sex, age category, diagnoses, work }\end{array}$ & $\begin{array}{l}\text { Partners } \\
\text { (individual } \\
\text { interviews) } \\
\text { sex, age } \\
\text { category, } \\
\text { work }\end{array}$ & Healthcare professionals \\
\hline $\begin{array}{l}\text { Rehabilitation } \\
\text { centre } \\
\text { Klimmendaal, } \\
\text { Arnhem }\end{array}$ & $\begin{array}{l}\text { 1. F, } 70-80 \text { years, } \\
\text { FSHD, not working } \\
\text { 2. F, } 60-70 \text { years, IBM, not } \\
\text { working }\end{array}$ & $\begin{array}{l}\text { 1. } \mathrm{F}, 40-50 \text { years, FSHD, not working } \\
\text { 2. } \mathrm{M}, 60-70 \text { years, HMSN, working } \\
\text { 3. } M, 60-70 \text { years, MM, working }\end{array}$ & $\begin{array}{l}\text { 1. } M, 70-80 \\
\text { years, not } \\
\text { working }\end{array}$ & $\begin{array}{l}\text { Individual interviews: } \\
\text { Rehabilitation physician }(n=1) \\
\text { Occupational therapist }(n=1) \\
\text { Physical therapist }(n=1)\end{array}$ \\
\hline $\begin{array}{l}\text { Community } \\
\text { health centre } \\
\text { Buitenlust, } \\
\text { Venray }\end{array}$ & $\begin{array}{l}\text { 3. F, } 60-70 \text { years, CPEO, } \\
\text { not working, drop out from } \\
\text { intervention group }\end{array}$ & $\begin{array}{l}\text { 4. } F, 60-70 \text { years, MM, not working } \\
\text { 5. F, 30-40 years, MM, working } \\
\text { 6. M, 60-70 years, HMSN, not working } \\
\text { 7. M, 40-50 years, FSHD, Working }\end{array}$ & - & $\begin{array}{l}\text { Individual interviews: } \\
\text { Occupational therapist }(n=1) \\
\text { Physical therapist }(n=1)\end{array}$ \\
\hline $\begin{array}{l}\text { Radboud } \\
\text { University } \\
\text { Medical } \\
\text { Centre, } \\
\text { Nijmegen }\end{array}$ & $\begin{array}{l}\text { 4. M, 50-60 years, MM, not } \\
\text { working } \\
5 . \mathrm{F}, 60-70 \text { years, IBM, not } \\
\text { working } \\
6 . \mathrm{F}, 50-60 \text { years, myasthenia } \\
\text { gravis, working } \\
7 . \mathrm{M}, 30-40 \text { years, MM, not } \\
\text { working dropped out from } \\
\text { intervention group }\end{array}$ & $\begin{array}{l}\text { 8. } M, 60-70 \text { years, FSHD, working } \\
\text { 9. } M, 40-50 \text { years, } M D \text {, not working } \\
\text { 10. F, 30-40 years, MD, working } \\
\text { 11. F, 70-80 years, FSHD, working } \\
\text { 12. F, 40-50 years, HMSN, not working }\end{array}$ & $\begin{array}{l}\text { 2. F, 60-70 } \\
\text { years, } \\
\text { working }\end{array}$ & $\begin{array}{l}\text { Individual interviews: } \\
\text { Rehabilitation physician }(n=1) \\
\text { Occupational therapists }(n=2) \\
\text { Neurologist }(n=1) \\
\text { Internist }(n=1) \\
\text { Secretary }(n=1) \\
\text { Physical therapist }(n=1) \\
\text { Member patient support } \\
\text { association }(n=1)\end{array}$ \\
\hline $\begin{array}{l}\text { Total } \\
\text { interviews }\end{array}$ & $\mathrm{n}=7$ & $\mathrm{n}=12$ & $\mathrm{n}=2$ & $n=13$ \\
\hline
\end{tabular}

CPEO, chronic progressive external ophthalmoplegia; F, female; FSHD, facioscapulohumeral dystrophy; HMSN, hereditary motor sensory neuropathy; IBM, inclusion body myositis; M, male; MD, myotonic dystrophy type 1; MM, mitochondrial myopathy.

the first author $(\mathrm{YV})$ and part of the transcript was also coded by the last author (EHCC) followed by comparison and discussion of the codes (YV/EHCC) to reach consensus on the coding procedure and content. In total 706 codes were found in the open coding process; (5) the first (YV) and last authors (HCE) identified potential 14 categories among the initial codes; (6) the potential categories were discussed by members of the research group (YV, EHCC, TS, MWGNvdS) and further grouped into final, main themes related to the research question; (7) the themes and description of the themes were emailed to all participants and they were asked if they could identify themselves with these themes. No further comments were given on the themes. The Consolidated criteria for Reporting Qualitative research checklist was used for reporting the qualitative data.

\section{Patient and public involvement}

Patients of our outpatient rehabilitation clinic (at Radboud University Medical Center) were involved in designing the Energetic programme. In a pilot study, qualitative research was conducted to improve the elements of the Energetic programme. ${ }^{17}$ The Energetic programme primarily addressed the patients' main research priority (ie, fatigue) as indicated by the research priorities of patients with NMD in general. ${ }^{18}$ No patient advisors were involved in designing the research questions or in the recruitment of this study. The Dutch NMD patient support association was involved in the recruitment of the participants in the RCT. This mixed methods evaluation gives insight in the experiences of patients regarding the Energetic programme, which also includes the burden of the intervention. The results from the individual and focus group interviews were sent to the participants and they were asked if they could identify themselves with the collected themes. The results of this study will be presented at congresses of the Dutch NMD patient support association and in their journals, which are sent to all members and are written in understandable language.

\section{Ethical considerations}

All patients gave their written informed consent to participate in the Energetic study. ${ }^{4}$ Furthermore, all participants in the current study signed an additional informed consent form prior to the interviews and questionnaires.

\section{RESULTS}

\section{Participants}

Patients and partners

Of the 29 patients in the Energetic programme 25 $(86 \%)$ completed the satisfaction questionnaires. Three patients dropped out of the intervention due to comorbidity $(n=1)$ or experienced too high a burden of the programme $(n=2)$. Ten patients were invited to participate in the interviews, of whom four declined due to practical reasons. Thus, six patients participated in the individual interviews (of which four patients completed the programme and two dropped out). In addition, two 
partners participated in the individual interviews. Of the other 19 patients who were asked to participate in the focus groups, seven patients declined to participate for practical reasons. Thus, 12 patients participated in the focus group interviews (see table 1 for details). Taken together, 18 out of 29 patients took part in the interviews (individual or focus group).

\section{Healthcare professionals}

All 13 healthcare professionals involved in the recruitment, organisation and delivery of the Energetic programme were interviewed. One professional was involved in the logistics and planning (secretary), five professionals were involved in the recruitment (four physicians and one representative of the patient association) and seven professionals were involved in the delivery of the programme (three PT and four OT).

\section{Satisfaction questionnaire}

The analysis of the satisfaction questionnaire (table 2) showed that $96 \%$ of the patients were entirely or largely satisfied with the results of the intervention. The mean grade of satisfaction with Energetic was 8.7 (SD 1.1) (scale 1-10). Management of the impairments was perceived as 'entirely' or 'largely' improved by $88 \%$ of the patients and the Energetic programme was 'largely' (32\%) or 'entirely'

Table 2 Patient satisfaction questionnaire regarding the results, delivery and content of the Energetic programme

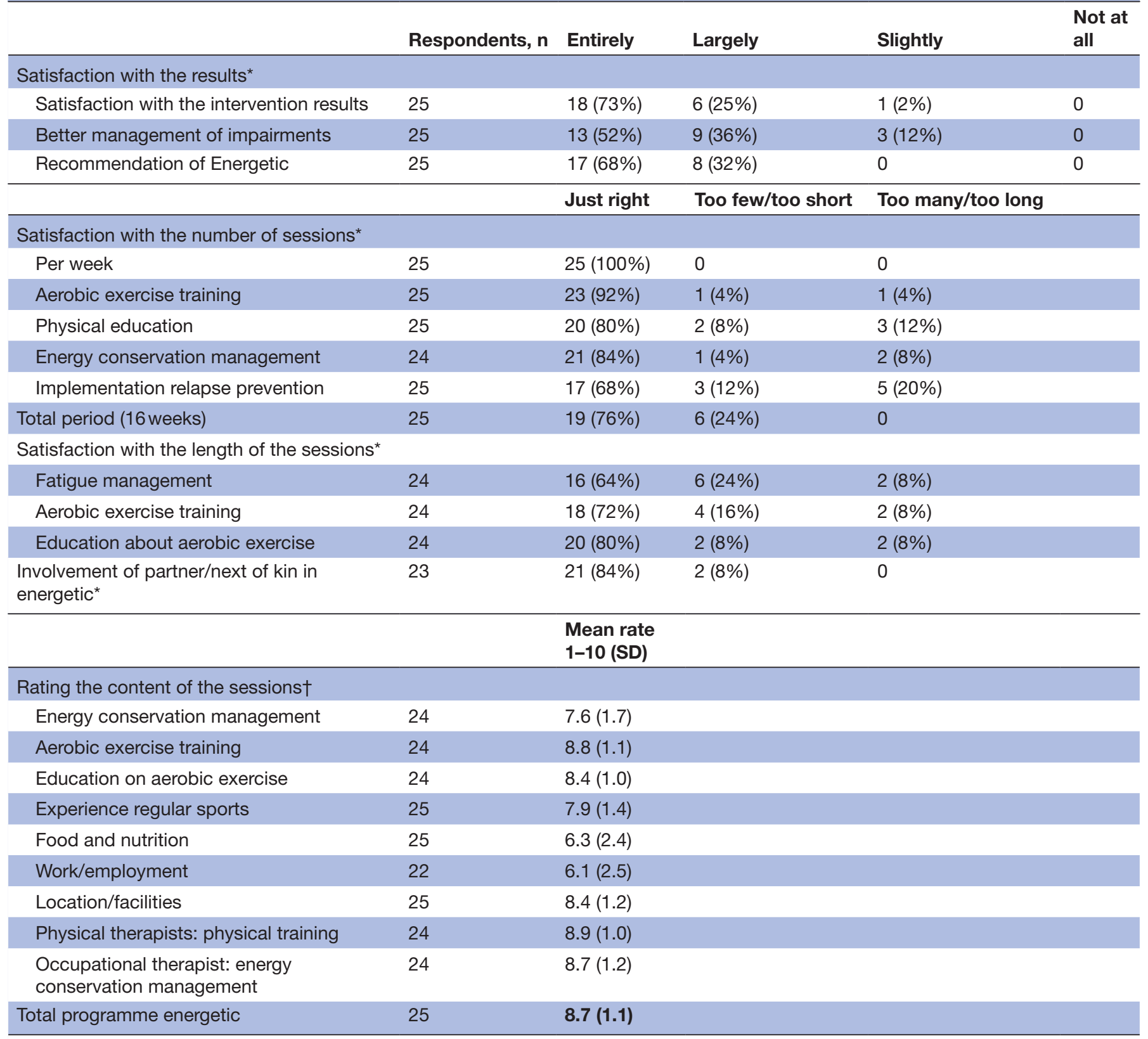

*Percentage responding patients with the number and length of sessions.

†Mean rating (standard deviation) of the content of the sessions by patients. 
$(68 \%)$ recommended to others/peers. Regarding the content of Energetic, patients were overall satisfied with the number and length of the sessions, as well as with the therapists and the different modules. In total, $24 \%$ of the patients evaluated the total period of 16 weeks as too short, whereas $20 \%$ considered the number of sessions in the implementation and relapse prevention module as too high. The sessions on nutrition and work were rated lower than other sessions.

\section{Interviews}

The interviews with patients, partners and healthcare professionals resulted in five main themes. Box 1 shows an overview of the main themes, subthemes and quotes. Each theme is described and supported by quotes from the participants.

\section{Themes}

The combination of modules makes a complete picture The combination of physical training and fatigue management gives insight into one's capacities

An important characteristic of Energetic for both patients and therapists was the combination of the four modules. Improvement of physical fitness, education about AET, applying ECM strategies and implementation of advice, training and strategies in daily life helped patients to get insight in their energy levels and physical capacities.

\section{The combination creates a complete picture. (PAN1)}

Patients reported that their participation level had increased, because they had become more aware of their possibilities to manage their energy in daily life.

I could, therefore, still participate in the cake decoration course, if I plan it in as part of my day programme. (PAA5)

The majority of patients reported that their physical fitness had improved. Additionally, most patients had become more aware of their own physical limitations and had gained a better understanding of how they could manage these limitations during physical activities.

After illness I have to slowly build the physical training programme up to a given point (PAA5)

The two partners reported that their spouses had learnt to better cope with the symptoms.

He has learnt to cope better mentally and that was very important for me. (NoK2)

\section{Being prepared to change lifestyle is pivotal}

Before the start of the programme both patients and therapists committed themselves to participation. An intake assessment was held with the patients to determine if they would be able to participate in the programme for 16 weeks and willing to integrate what
Box 1 Overview of patients', partners' and healthcare professionals' perspectives regarding the content and delivery of the energetic programme

\section{Themes and subthemes}

1. The combination of modules makes a complete picture.

A. The combination of physical training and fatigue management gives insight into one's capacities

The combination creates a complete picture. (PAN1)

I could, therefore, still participate in the cake decoration course, if I plan it in as part of my day programme. (PAA5)

After illness I have to slowly build the physical training programme up to a given point. (PAA5)

He has learnt to cope better mentally and that was very important for me. (CG2)

B. Being prepared to change lifestyle is pivotal

We were all prepared to change things in our lifestyle, to adapt things and to try new things. (PAV2)

C. Sustainability of implementation in daily life is essential A step-by-step guide was provided that could easily be applied practically. (PAN8)

Good to correct the entrenched deviations and also ask a huge amount of questions. (PAA5)

D. Sport's participation in one's own environment challenging

They had already approached clubs before we had finished the Energetic programme. (OT)

The different sports activities could be placed earlier in the programme, so that I can find out what is good for me. (PAN2)

2. The programme is physically and mentally intensive

The conversation was exhausting, more difficult and more confrontational than expected. (PAA3)

The afternoon hours with the occupational therapist were often a bit tedious. (PAA5)

The session on nutrition could have been more. (PAN2)

I had underestimated the time. It cost me a lot more time than expected. This made it difficult to plan in with my home situation. (PAV5)

All consultations were useful and important for me. (PAA3)

The Energetic programme is an extremely complex programme to plan and organise. (SC)

3. The group setting is valuable

We learn from each other. (PAV5)

We encourage each other. (PAA5)

Within the group, different approaches and viewpoints are heard - it does not always come from the therapist. (OT)

In future, there needs to be more time for individual questions of all participants, because this time there were two people who dominated time with their questions about looking for work and hobby participation. (OT)

4. Small variation in delivery in different settings

Some of the bicycles are a little heavier, then patients (from other therapists) just had to go on those because my patients need a lighter bike. This was always discussed and ended up not being a problem. (PT)

I found that planning the sports sessions was always labour intensive and needed a lot of explanation towards management. (PT)

5. Therapists are coaches

allowing us to think outside of the box. (PAA5)

real interest. (PAV2)

expertise. (PAA4) 


\section{Box 1 Continued}

Guiding a group and encouraging 'change language' is not something you can learn really quickly and easily in one training session. (OT)

A. Therapists need education

It was really stimulating in terms of the learning activities; it was varied in theory and practice in terms of what needed to be done on the programme. (PT)

You obtain the information, but you can only really engage in conversation about it when you have tried to apply it yourself. (PT)

Then you can hear from everyone about how it went. (OT)

they would learn into their everyday lives. They also identified what they wanted to achieve through participation in the Energetic programme.

We were all prepared to change things in our lifestyle, to adapt things and to try new things. (PAV2)

\section{Sustainability of implementation in daily life is essential}

The steady structure in the programme, the translation to practical situations and the integration in daily routines were experienced as valuable.

A step-by-step guide was provided that could easily be applied practically. (PAN8)

Three months after completion of the programme there was a booster session, which was valued as positive by most patients.

Good to correct the entrenched deviations [after three months] and also ask a huge amount of questions. (PAA5)

Several patients reported that they would appreciate more booster sessions in the future to be better able to retain the newly learnt behaviours in everyday life.

\section{Sports participation in one's own environment is challenging}

An important element of the Energetic programme is the guidance offered to implement sports activities in everyday life. Therapists reported that most patients actively sought possibilities for sports participation. Some patients actually joined a sport in their own environment after completing the programme.

They had already approached clubs before we had finished the Energetic programme. (OT)

However, others reported that they could not find a suitable sports activity. They expressed the wish for more support in seeking appropriate sports activities in their neighbourhood

The sports sessions that were presented as part of the programme were positively valued, but also difficult to perform. A few patients would have liked the sports sessions to be presented earlier in the programme, so that they would have had more time to search and implement an appropriate sport.
The different sports activities could be placed earlier in the programme, so that I can find out what is good for me. (PAN2)

\section{The programme is physically and mentally intensive}

Both patients and healthcare professionals described Energetic as an intensive programme on many levels. Most patients mentioned the physical training as a factor that contributed to the intervention burden. In addition, the mental strain of having to evaluate and reflect on one's own behavioural patterns was also experienced as burdensome.

The conversation was exhausting, more difficult and more confrontational than expected. (PAA3)

Some patients reported that the frequency and duration of the sessions were exhausting in the context of everyday life, whereas others reported that Energetic fitted well within their daily routine. By some, the travel distance to the programme was mentioned as a stressor.

I had underestimated the time. It costed me a lot more time than expected. This made it difficult to plan in with my home situation. (PAV5)

Regarding the content of the programme, some patients mentioned that the ECM sessions were long and contained repetitions of theories.

The afternoon hours with the occupational therapist were often a bit tedious. (PAA5)

For some patients, the session on the topic of work was not applicable as they were no longer working (after retirement or cessation of work due to the consequences of NMD). The session on nutrition was perceived by some patients as too short and, therefore, lacking depth.

The session on nutrition could have been more. (PAN2)

Nevertheless, most patients reported that they would not like to see any element of the programme being deleted.

All consultations were useful and important for me. (PAA3)

The healthcare professionals reported the complex planning of the programme within their work schedule as intensive.

The Energetic programme is an extremely complex programme to plan and organise. (SC)

\section{The group setting is valuable}

All patients and healthcare professionals reported that they experienced the group setting as valuable in order to share experiences, to learn from others and to motivate each other. 
We learn from each other' (PAV5), 'We encourage each other' (PAA5), 'Within the group, different approaches and viewpoints are heard - it does not always come from the therapist. (OT)

Both therapists and patients reported a group of six patients as optimal to be able to focus on all personal dilemmas and questions. One patient and one therapist explicitly expressed that they did not have enough time for individual questions.

In future, there needs to be more time for individual questions of all participants, because this time there were two people who dominated time with their questions about looking for work and hobby participation. (OT)

\section{Small variations in delivery occur in different settings}

The Energetic programme was offered in a variety of clinical settings. Patients and therapists reported that practical solutions needed to be found at the various locations.

Some of the bicycles are a little heavier. Then patients (from other therapists) just had to go on those because my patients needed a lighter bike. This was always discussed and ended up not being a problem. (PT)

It also became apparent that the different clinical settings organised certain details differently. At the rehabilitations centre, for example, $5 \mathrm{~min}$ of Tai Chi was performed by means of a warm up before the training. The sports sessions were organised at a regular sports complex outside the centre. The costs hereof were not covered by the medical insurance and therapists from two settings experienced this as a draw-back.

I found that planning the sports sessions was always labour intensive and needed a lot of explanation towards management. (PT)

\section{Therapists are coaches}

Patients and therapists alike reported that therapists adopted the role of a 'coach' during the programme. The therapists also reported that the collaboration between them (OT and PT) was important to guide the group well.

The therapist's characteristics that patients found important were 'expertise' (PAA4), 'real interest' (PAV2), and 'allowing us to think outside of the box' (PAA5). A few patients reported that they found the guidance from the therapists insufficient and lacking attention regarding individual differences. Additionally, some therapists reported that supervising an entire group required a lot of attention.

Guiding a group and encouraging 'change language' is not something you can learn really quickly and easily in one training session. (OT)

\section{Therapists need education}

The education programme for therapists was experienced as valuable.

It was really stimulating in terms of the learning activities; it was varied in theory and practice in terms of what needed to be done on the programme (PT)

A few therapists reported that they would have preferred less time between workshop sessions to prepare for the Energetic programme in their own setting. They liked obtaining the theory and then being able to implement in daily life what they had learnt.

You obtain the information, but you can only really engage in conversation about it when you have tried to apply it yourself. (PT)

The therapists reported that interaction among peers was important for everyone's learning process. The practice experiences were shared during the group supervision.

Then you can hear from everyone about how it went. (OT)

\section{DISCUSSION}

A mixed methods evaluation of the Energetic programme showed a diverse picture of the facilitators and barriers related to the content and delivery of this multidisciplinary outpatient group intervention for patients with NMD and chronic fatigue.

The patients' insight in their own capacities and improved participation level was consistent with the aim of the Energetic programme and with the observed improvement on the primary outcome of our RCT, the COPM. ${ }^{6}$ The COPM measures experienced problems in activities that are important and meaningful for an individual. ${ }^{19} 20$ The choice of the COPM as a primary outcome fits with the client-centred approach of Energetic and with the impact reported by patients in this evaluation. Moreover, the perceived improvement of physical fitness reported by patients was in line with the observed improvement of physical endurance as measured with the 6 min walking test in our RCT. ${ }^{6}$ To measure insight into patient's own capacities, the general self-efficacy scale (GSES) was used, which showed no group difference or change over time. However, the GSES is not specifically designed for the selfefficacy to implement energy conservation strategies. An alternative self-efficacy assessment developed by Liepold et $a l^{21}$ specifically evaluates self-efficacy in performing ECM strategies and might be a possible valuable measure in future programme evaluations.

Patients and healthcare professionals reported that the group setting supported the patients to learn from their own experiences, as well as from each other, with the therapists taking the role of a coach. Such vicarious experiences, including verbal (social) persuasion, fit well with Bandura's self-efficacy theory, ${ }^{22}$ are believed to support 
behavioural change. In addition, guidance in embedding AET and ECM strategies by self-monitoring behaviour and receiving feedback from peers may contribute to patients' self-management capacities. ${ }^{93}$ However, in this evaluation, some patients reported that, despite this guidance, they found it difficult to implement exercising at home and maintain the acquired skills in the long term. This is in line with a study of Wallace where patients mentioned a high motivation to maintain exercising after a training programme, but experienced barriers to gym membership and implementation. ${ }^{24}$ This phenomenon has been described by Packer, who emphasised that self-management is an ongoing process requiring continuous effort and support to gain knowledge, skills and confidence over time. ${ }^{25}$ Additional booster sessions are, therefore, recommended to enable trial-and-error practice in a constantly changing context and to receive encouragement from peers and knowledgeable healthcare professionals. These booster sessions should focus on the maintenance of exercising, planning and pacing in daily life taking into account the progressive character of the disease and the changing roles and context.

During the interviews, patients reported a high willingness to change before the start of the programme, which was probably related to the motivational screening by occupational therapists before participation. The screening for (in) eligibility before the start of the RCT regarded the individual motivation to change behaviour and the expected individual intervention burden, which resulted in an exclusion of 43 patients. ${ }^{6}$ Nevertheless, in the interviews, the Energetic programme was reported to be physically and mentally intensive and sometimes difficult to schedule within the weekly agenda, which also depended on travel distance. This perceived intervention burden is an important factor for patients' willingness to participate in Energetic and should be clear during the screening for patients at the start of the programme. However, in the interviews, patients reported that no elements should be taken out of the programme. A way to reduce the intervention burden would be the use of blended care, for instance, combining e-health and faceto-face sessions. ${ }^{26} 27$ The recent developments during the COVID-19 pandemic, for instance the increase in video calls for regular healthcare, show that e-health can be used in combination with traditional forms of care in outpatient rehabilitation. ${ }^{28}$

The results of this study suggest that Energetic can be delivered in a rehabilitation centre, in a specialised hospital department, as well as in a primary care setting. Only minor practical adjustments were necessary per setting. The collaboration among therapists within and between settings was considered to be a facilitating factor for the delivery of the programme. This is in line with the study by van Dongen $e t a l^{29}$ who identified facilitating factors for interdisciplinary collaboration, such as knowing each other well, organisational factors regarding the delivery of a intervention and professional meetings, and having a shared vision. Additionally, they stressed the importance of a team leader who plays a key role in overseeing the organisation and guiding the team through the developments. ${ }^{29}$ Due to the complexity in the organisation and planning of the programme we, therefore, suggest that every clinical setting should assign a team leader to implement Energetic.

Both therapists and patients experienced that guiding a group requires specific skills for therapists. Therapist are trained in individual consultations with patients, suggesting that specific group didactic skills would be helpful to optimise the group interaction within Energetic. Finally, finding finances for the external sports sessions was reported by therapists as a barrier. Regular sports activities in society are organised outside the healthcare setting and, thus, are not within the traditional scope of most therapists and not financially reimbursed by healthcare insurances. For better implementation of this aspect of the Energetic programme, collaboration with governmental sports organisations and healthcare professionals working in regular sports domains should be considered. ${ }^{30}$

\section{Strengths and limitations}

We tried to optimise the credibility of our results by including the perspectives of patients, partners and healthcare professionals. ${ }^{31}$ Furthermore, we used independent interviewers for the individual and focus group sessions, independent research assistants to establish the coding structure's validity, and we emailed the themes to all participants and asked if they could identify themselves with these themes. We have followed different strategies to enhance the trustworthiness of the findings: triangulation of data collection methods and triangulation of researchers (use of two researchers for data collection and analysis). Furthermore, reflective meetings with the research group to discuss the analytical process and the preliminary and final themes enhanced the credibility of our data. ${ }^{32}{ }^{33}$ Nevertheless, qualitative research and satisfaction questionnaires reflect the perceived impact and interpretation of the programme by patients and professionals, which does not allow causal inferences. Another methodological limitation is that only two partners participated, which inevitably has led to lack of saturation regarding the partners' perspectives. In addition, the fact that the satisfaction questionnaires were only filled in by patients who completed the intervention can be considered a methodological limitation, because it may have led to selection bias. Yet, we gained some insight also in the experiences of those who dropped out by interviewing two patients that discontinued the intervention because of its intensity or due to comorbidities.

\section{CONCLUSION}

This mixed methods evaluation was conducted to investigate the experiences of patients and healthcare professionals involved in a multidisciplinary outpatient self-management group programme called Energetic. 
The aim of this programme is to improve social participation and physical endurance in people with NMD and chronic fatigue. Patients were overall satisfied with the number and length of the sessions, as well as with the therapists and the different modules. Our results indicate that Energetic can be implemented in different clinical settings and that the use of group sessions and using a combination of AET, education about AET, ECM and dailylife implementation are facilitators for attaining better self-management. Patient suggestions for programme improvement are the use of blended care interventions, inclusion of more booster sessions and more guidance in seeking appropriate sports activities in the personal environment. As for the therapists, suggested improvements included enhancement of group supervising skills and collaboration between therapists and society or governmental sports organisations.

\section{Author affiliations}

${ }^{1}$ Department of Rehabilitation, Donders Institute for Brain, Cognition and Behaviour, Radboud university medical center, Nijmegen, The Netherlands

${ }^{2}$ School of Occupational Therapy, HAN University of Applied Science, Nijmegen, The Netherlands

${ }^{3}$ IQ Healthcare, Research Institute for Health Sciences, Radboud university medical center, Nijmegen, The Netherlands

${ }^{4}$ Department of Neurology, Donders Institute for Brain, Cognition and Behaviour, Radboud university medical center, Nijmegen, The Netherlands

Acknowledgements The study was funded by the Netherlands Organisation for Health Research and Development (ZonMw), grant number 837001402, National Rehabilitation Fund (Revalidatiefonds) and Centre of Expertise 'Sneller herstel' (HAN). We thank Radboud into languages for their editing service. We thank all patients and their next of kin for their participation. We thank the students of the HAN University of Applied Sciences, School of Occupational Therapy, research assistant Group 1: Natasja Wouda, Wietske Berendsen, Dieke Bos, Madelief Tiel Groenestege, and research assistants Group 2: Laura van Nüss, Maaike Schell, Daphne Schuhmacher and Chantal Szczyrba for organising and conducting the interviews. We also thank the healthcare professionals who delivered Energetic: Petra Diederiks, Lidwien Roeling (PT), Christel Groenier and Anne Schutter (OT) from rehabilitation centre Klimmendaal (Arnhem); Martine Josten (OT), Bram Cruijsen and Ewald Overbeek (PT) from community health centre Buitenlust (Venray); and Suzanne van Hees, Nanette Nab (OT) and Tamara Popping (PT) from Radboud University Medical Center (Nijmegen). Additionally, we thank Anja Horemans and Anke Groenen from the patient support association 'Spierziekten Nederland' and Yvonne Cornelissen for her help with patient recruitment. We also thank Jana Zajec and Bart Kral from Radboud university medical center for their assistance in the assessments. We thank Margot Barry and Radboud into languages for translating the Dutch patient quotes to English. Finally, we thank Laurien Honing for her administrative assistance. Several authors of this publication are members of the Netherlands Neuromuscular Center (NL-NMD) and the European Reference Network for rare neuromuscular diseases (EURO-NMD).

Contributors YV, HCE, BGMvE and AG conceptualised the study and coordinated funding. W undertook and monitored the study with supervision from HCE, JTG, AG, TS and MWGNvdS. YV was responsible for supervising the therapists, research assistants and recruited patients. YV and HCE led the data analysis. YV, HCE, TS and RN-vdS interpreted data. YV and HCE, TS and MWGNvdS wrote the first draft of the manuscript and were responsible for revisions. YV, HCE, TS, MG, MWGNvdS, BGMvE and AG discussed and commented on draft versions. All authors approved the final version.

Funding This investigator-initiated study was supported by the Netherlands Organisation for Health Research and Development (ZonMw), grant number 837001402, National Rehabilitation Fund (Revalidatiefonds) and Centre of Expertise 'Sneller herstel' (HAN). The study sponsors had no role in designing the study, patient recruitment, data collection, data analysis, data interpretation, writing of the report or submitting papers for publication. The corresponding author has full access to all study data and holds the final responsibility for the decision to submit this work for publication.
Competing interests YV was sponsored by the Netherlands Organisation for Health Research and Development (ZonMw), National Rehabilitation Fund and Centre of Expertise 'Sneller Herstel' (HAN) and the Dutch FSHD Foundation. EHCC was sponsored by the Netherlands Organisation for Health Research and Development (ZonMw), National Rehabilitation Fund and Centre of Expertise 'Sneller Herstel' (HAN) the Dutch FSHD Foundation. She also reports grants from the Prinses Beatrix Spierfonds. BGMvE was sponsored by the Netherlands Organisation for Health Research and Development (ZonMw), National Rehabilitation Fund and Centre of Expertise 'Sneller Herstel' (HAN). He also reports grants from the EU Horizon 2020 research and innovation programme (Murab), the Netherlands Organisation for Scientific Research, the Netherlands Organisation for Health Research and Development, Global FSH, Prinses Beatrix Spierfonds, Stichting Spieren voor Spieren, Association Francaise contre les Myopathies, Fulcrum and the Dutch FSHD Foundation. ACHG was sponsored by the Netherlands Organisation for Health Research and Development (ZonMw), National Rehabilitation Fund and Centre of Expertise 'Sneller Herstel' (HAN). He also reports grants from the Netherlands Organisation for Scientific Research (ZonMw), the Netherlands Organsation for Health Research and Development, Prinses Beatrix Spierfonds, National Rehabilitation Fund, Ipsen, Merz and Otto Bock. JTG reports grants from Prinses Beatrix Spierfonds and Fulcrum Therapeutics. TS, MJLG and MWGNvdS declare that there is no conflict of interest.

Patient consent for publication Not required.

Ethics approval Full ethical approval was granted by the medical ethical committee of the region Arnhem-Nijmegen (NL47624.091.14) and the executive boards of all participating centres. All patients provided oral and written informed consent. The trial was registered at clinicaltrial.gov (NCT02208687).

Provenance and peer review Not commissioned; externally peer reviewed.

Data availability statement Data are available upon reasonable request. All data used and analysed during the current study are available from the corresponding author on reasonable request until 2026.

Supplemental material This content has been supplied by the author(s). It has not been vetted by BMJ Publishing Group Limited (BMJ) and may not have been peer-reviewed. Any opinions or recommendations discussed are solely those of the author(s) and are not endorsed by BMJ. BMJ disclaims all liability and responsibility arising from any reliance placed on the content. Where the content includes any translated material, BMJ does not warrant the accuracy and reliability of the translations (including but not limited to local regulations, clinical guidelines, terminology, drug names and drug dosages), and is not responsible for any error and/or omissions arising from translation and adaptation or otherwise.

Open access This is an open access article distributed in accordance with the Creative Commons Attribution Non Commercial (CC BY-NC 4.0) license, which permits others to distribute, remix, adapt, build upon this work non-commercially, and license their derivative works on different terms, provided the original work is properly cited, appropriate credit is given, any changes made indicated, and the use is non-commercial. See: http://creativecommons.org/licenses/by-nc/4.0/.

ORCID iD

Yvonne Veenhuizen http://orcid.org/0000-0003-0294-4403

\section{REFERENCES}

1 Kalkman JS, Schillings ML, van der Werf SP, et al. Experienced fatigue in facioscapulohumeral dystrophy, myotonic dystrophy, and HMSN-I. J Neurol Neurosurg Psychiatry 2005;76:1406-9.

2 Kalkman JS, Zwarts MJ, Schillings ML, et al. Different types of fatigue in patients with facioscapulohumeral dystrophy, myotonic dystrophy and HMSN-I. Experienced fatigue and physiological fatigue. Neurol Sci 2008;29:238-40.

3 Lou J-S, Weiss MD, Carter GT. Assessment and management of fatigue in neuromuscular disease. Am J Hosp Palliat Care 2010;27:145-57.

4 Veenhuizen Y, Cup EHC, Groothuis JT, et al. Effectiveness and costeffectiveness of a self-management group program to improve social participation in patients with neuromuscular disease and chronic fatigue: protocol of the energetic study. BMC Neurol 2015;15:58.

5 Packer N, Sauriol A. Managing fatigue: a six-week course for energy conservation. Tucson: AZ: Therapy Skill Builders, 1995.

6 Veenhuizen Y, Cup EHC, Jonker MA, et al. Self-management program improves participation in patients with neuromuscular disease: a randomized controlled trial. Neurology 2019;93:e1720-31. 
7 Paterson BL. The shifting perspectives model of chronic illness. J Nurs Scholarsh 2001;33:21-6.

8 Holman H, Lorig K. Patient self-management: a key to effectiveness and efficiency in care of chronic disease. Public Health Rep 2004;119:239-43.

9 Michie S, Richardson M, Johnston M, et al. The behavior change technique taxonomy (V1) of 93 hierarchically clustered techniques: building an international consensus for the reporting of behavior change interventions. Ann Behav Med 2013;46:81-95.

10 Oakley A, Strange V, Bonell C, et al. Process evaluation in randomised controlled trials of complex interventions. BMJ 2006;332:413-6.

11 Malterud K. Qualitative research: standards, challenges, and guidelines. Lancet 2001;358:483-8.

12 Tariq S, Woodman J. Using mixed methods in health research. JRSM Short Rep 2013;4:2042533313479197.

13 Moore GF, Audrey S, Barker M, et al. Process evaluation of complex interventions: medical research council guidance. BMJ 2015;350:h1258.

14 Kallio H, Pietilä A-M, Johnson M, et al. Systematic methodological review: developing a framework for a qualitative semi-structured interview guide. J Adv Nurs 2016;72:2954-65.

15 Yilmaz K. Comparison of quantitative and qualitative research traditions: epistemological, theoretical, and methodological differences. Eur J Educ 2013;48:311-25.

16 Carter SM, Little M. Justifying knowledge, justifying method, taking action: epistemologies, methodologies, and methods in qualitative research. Qual Health Res 2007;17:1316-28.

17 Cup E, Nab N, Maas D, et al. S.P.45 energetic, a multidisciplinary self-management group program for reconditioning and managing fatigue. Neuromuscular Disorders 2012;22:896-7.

18 Nierse CJ, Abma TA, Horemans AMC, et al. Research priorities of patients with neuromuscular disease. Disabil Rehabil 2013;35:405-12.

19 Dedding C, Cardol M, Eyssen ICJM, et al. Validity of the Canadian occupational performance measure: a client-centred outcome measurement. Clin Rehabil 2004;18:660-7.

20 Eyssen ICJM, Beelen A, Dedding C, et al. The reproducibility of the Canadian occupational performance measure. Clin Rehabil 2005;19:888-94.
21 Liepold A, Mathiowetz V. Reliability and validity of the self-efficacy for performing energy conservation strategies assessment for persons with multiple sclerosis. Occup Ther Int 2005;12:234-49.

22 Bandura A. Health promotion from the perspective of social cognitive theory. Psychol Health 1998;13:623-49.

23 Moss-Morris R, Norton S. Aerobic exercise, cognitive behavioural therapy and energy conservation management for multiple sclerosis (MS) fatigue: are three trials better than one? Mult Scler 2017;23:1436-40.

24 Wallace A, Pietrusz A, Dewar E, et al. Community exercise is feasible for neuromuscular diseases and can improve aerobic capacity. Neurology 2019;92:e1773-85.

25 Packer TL. Self-management interventions: using an occupational lens to rethink and refocus. Aust Occup Ther J 2013;60:1-2.

26 Ghahari S, Packer T. Effectiveness of online and face-to-face fatigue self-management programmes for adults with neurological conditions. Disabil Rehabil 2012;34:564-73.

27 Wentzel J, van der Vaart R, Bohlmeijer ET, et al. Mixing online and face-to-face therapy: how to benefit from blended care in mental health care. JMIR Ment Health 2016;3:e9.

28 Negrini S, Kiekens C, Bernetti A, et al. Telemedicine from research to practice during the pandemic. "Instant paper from the field" on rehabilitation answers to the COVID-19 emergency. Eur J Phys Rehabil Med 2020;56:327-30.

29 van Dongen JJJ, Lenzen SA, van Bokhoven MA, et al. Interprofessional collaboration regarding patients' care plans in primary care: a focus group study into influential factors. BMC Fam Pract 2016;17:58.

30 Sport en bewegen voor iedereen (sports for everyone), 2019. Available: https://www.rijksoverheid.nl/onderwerpen/ sport-en-bewegen/sport-voor-mensen-met-een-beperkingmigratieachtergrond-laag-inkomen2019

31 Graneheim UH, Lundman B. Qualitative content analysis in nursing research: concepts, procedures and measures to achieve trustworthiness. Nurse Educ Today 2004;24:105-12.

32 Devers KJ. How will we know "good" qualitative research when we see it? Beginning the dialogue in health services research. Health Serv Res 1999;34:1153-88.

33 Carter N, Bryant-Lukosius D, DiCenso A, et al. The use of triangulation in qualitative research. Oncol Nurs Forum 2014;41:545-7 